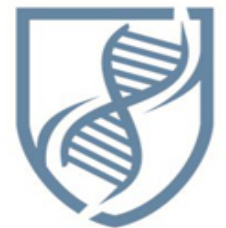

Journal of Bioscience and Applied Research
JBAAR

WWW.JBAAR.ORG

\title{
Comparative studies on the adaptive renal structures of some teleost fish species inhabiting different habitats
}

\author{
Zeinab M. El-Gohary; Manal, M. Ramadan; Souad, A. Khalifa; Tasneem, R. Ebraheem \\ Zoology Dept., Faculty of Science, Mansoura University, Egypt
}

\begin{abstract}
The present study was conducted to elucidate and compare the adaptive renal structures of freshwater, Bagrus bayad, brackish water Tilapia zilli and seawater Scomber japonicus. The trunk kidneys of the selected fish species were investigated morphometrically, histologically and ultrastructurally. The recorded results showed that the nephrons of Bagrus bayad and Tilapia zilli were distributed within the renal tissue as clusters, while those of Scomber japonicus were scattered solitary within the renal tissue. Bagrus bayad displayed abundant of well vascularized large glomeruli along with thin filtration barrier and numerous wide filtration slits as well as numerous mitochondria of both proximal and distal tubules. However, Scomber japonicus exhibited few number of small glomeruli along with abundance mesangial cells, extremely narrow filtration slits and relatively thick filtration barrier as well as unique giant mitochondria. The structural organizations of the Tilapia zilli nephrons were inter-between Bagrus bayad and Scomber japonicus. As a whole, the results of the current study showed that the kidney of the examined fish species exhibited specific adaptive renal structural features to fulfill their variable osmoregulatory demands.
\end{abstract}

Key words: Teleost fish, habitat, renal structure , adaptive features

\section{Introduction}

It is well established that teleost fishes have developed remarkable mechanisms for coping with life in diverse aquatic environments; freshwater, brackish and seawater, each of which is quite variable with respect to the salinity.
Therefore, it is an essential prerequisite for teleost to maintain body fluid homeostasis within narrow limits across a wide range of salinities. Kidneys do play a role in osmoregulation, but overall, extra-renal organs are equally if not more important sites for maintaining osmotic homeostasis (Evans et al., 2005; Hwang \& Lee, 2007).

In freshwater environment, the teleost fish is hyperosmotic to the habitat, thus ions diffuse out, and water moves into the fish. The kidney retain ions and excretes water by elaborating huge volume of highly diluted urine. On contrast, seawater teleosts are hypo-osmotic to the habitat, so they subjected to water loss and salt load, consequently the kidney excretes ions and conserves water (Jensen et al., 1998; Reimschuessel, 2001; Hawkins et al., 2004).

The kidney is considered as the primary osmoregulatory organ not only in fish but also among all the different vertebrate classes (Jarial \&Wilkins , 2010; Engelund \& Madsen, 2011 ). It implicated in the maintenance of body fluid homeostasis regardless to the nature of the habitat (Ojeda et al., 2003).

The different teleost fish species have one pair of mesonephros retroperitoneal kidneys (Drummond, 2000), situated ventrally to the vertebral column inside the abdominal cavity. They are typically narrow, elongated organs, occupying a significant portion of the trunk. Each kidney consists of two portions; head kidney and trunk kidney (Koc, 2006; Silva \& Martinez, 2007). The gross anatomy of the kidney varies in different species from distinctly bilobed head and trunk kidneys, to kidneys that are fused and intimately embedded between the vertebrae (Ogawa, 1962). The head kidney contains predominantly hematopoietic, lymphoid; and chromaffin tissues 
(Wendelaar Bonga, 1997). The trunk kidney is composed of the excretory tissues (nephrons) with variable quantities of hemopoietic and lymphoid tissue in the interestitium (Hentschel \& Elger, 1988).

The morphological and structural organizations of the kidneys of the different freshwater and marine fish species have frequently been studied using light and electron microscopic techniques by Morales et al. (1990) on Mugil cephalus L., Charmi et al. (2009) on beluga, Huso huso, Jarial \&Wilkins (2010) On Liza saliens Risso, Mohinder et al. (2014) on Latimeria chalumnae.

The typical fish kidney is made up of numerous individual units or nephrons, each of which consisted of a renal corpuscle and renal tubules of variable length (Silva \& Martinez, 2007; Jarial \&Wilkins, 2010; Prashanth, 2011). The renal corpuscle composed of a glomerulus which enclosed by a cup-shaped double layered structure; Bowman `capsule (Das \& Srivastava, 1980). While, the renal tubules are structurally differentiated into five cytologically distinct regions. (Anderson \& Loewwn, 1975).

In teleost fishes, there are close correlation between the structural features of the nephron and the nature of their habitat specifically in terms of salinity. The nephron of freshwater fish typically has a well-vascularized glomerulus, a ciliated neck segment, two proximal segments, a ciliated intermediate segment, a distal segment, and a collecting duct system. However, in marine teleosts the nephrons are weakly developed and in some, there are neither glomeruli nor distal tubules as in Sparus auratus (Dantzler, 2003).

Despite the several studies concerning either the structural or the functional features of the teleost fish kidney, there is a paucity of information deals with comparative studies on the adaptive renal structural aspects among different teleost fishes inhabiting different habitats. Therefore, the current study was designed to clarify in more details the adaptive renal structural aspects of the different teleost fishes inhabiting diverse habitats. The renal morphometric , histologic and ultrastructural configurations were investigated in fishes inhabiting fresh water (Bagrus bayad ), or brakish water (Tilapia zilli) or sea water (Scomber japonicas ) habitats in order to reveal the adaptive renal structural features that could be related to the nature of habitats.

\section{Materials and Methods}

\section{1- The investigated fish species}

In the present study, the selected fish species were included freshwater, Bayad (Bagrus bayad), Brackish water, Green tilapia (Tilapia zilli) and seawater, Chub mackerel (Scomber japonicas). All the different fish species belong to class osteichthyes. They inhabit vastly different ecological niches in terms of water salinity. Bayad (Bagrus bayad) is exclusively stenohaline freshwater fish species. Prey on small fish, insects, mollusks and vegetable matter (Malami \& Magawata, 2010 ). They were caught from the Damietta branch of the River Nile in Dakahlia Governorate, off Mansoura, Egypt.

Green tilapia (Tilapia zilli) is euryhaline species. They inhabit estuarine habitats, lakes. Adults are herbivorous typically feed on detritus, filamentous algae, aquatic macrophytes and plants (Crutchfield et al. 1992). The specimens of the studied Tilapia zilli were caught from the brackish water of the Lake Manzala.

Chub mackerel (Scomber japonicus) is an active pelagic fish species. They feed mainly on Pisces, crustaceans and annelids (Rizkalla \& Faltas, 1997). The specimens of Chub mackerel were caught from Mediterranean, off Balteem.

All the selected fish species were caught from their natural habitat, after which they were transported to the laboratory in fiber glass tank containing the specific media of each species separately. All the collected fishes were adult and healthy. Fifteen male fishes were used for each studied species regardless to body weight.

The different selected fish species were killed by cervical dislocated in the case of tilapia and chub mackerel while bayad were sacrificed using sharp knife, then they were dissected to remove out the kidneys for morphological investigation, light and transmission electron microscopy. The present work considered and focused on the trunk kidney of the different studied fish species, since it presented the excretory part of the fish kidney and in turn the osmoregulatory organ.

\section{II- Macroscopic \& Microscopic Studies}

\section{1-Nephron Enumeration}

The number of nephrons was counted in half gram of the fresh renal tissue of the trunk portion of the kidneys of the different examined fish species following the method described by Maluf (1991).

\section{2- Histological Preparation}

Specimens of the trunk kidneys of the different studied species were fixed in $10 \%$ neutral buffered formalin. The fixed samples were washed by tap water, then dehydrated by routine methods utilizing ascending concentrations of ethyl alcohol, after which they were cleared in xylol and embedded in paraffin wax (Akhundov \& Federove, 1995). The samples were sectioned to a thickness of $7 \mathrm{~m}$, and stained with hematoxylin and eosin, using standard histology methods (Bancroft \& Gamble, 2002).

\section{3- Morphometric Studies}

The stained kidney sections of the different studied fish species were used to enumerate the number of the glomeruli per each microscopic field at magnification power of $40 \mathrm{X}$ for seven different areas of five slids and the mean number was calculated following the method of Altschuler et al.(1979). Also, the diameters of at least ten glomeruli were measured in five slides for each investigated kidney using light microscope fitted with ocular micrometer eye piece at magnification power of 
100X. (Solomon,1974). Average glomerular diameters were computed and the glomerular volume $(\mathrm{GV})$ was calculated using the average radius (r) applying the following equation : $\mathrm{GV}=4 / 3 \pi \mathrm{r} 3$ whereas the glomeruli were treated as spheres as previously reported by kunkel (1930). The total glomerular volume (TGV) was computed as an index of the glomerular filtration surface area. TGV = mean number of total glomeruli /each microscopic area $\mathrm{x}$ mean volume of glomeruli.

\section{Ultrastructural preparation}

Samples consisting of small pieces $(1 \mathrm{~mm} 3)$ of the renal tissue of the studied species were excised and fixed in $2.5 \%$ glutaraldehyde buffered to $\mathrm{pH} 7.3$, with $0.1 \mathrm{M}$ phosphate buffer for $2 \mathrm{~h}$ at $4 \mathrm{oC}$. For transmission electron microscopy (TEM), fixed pieces of the renal tissues were post-fixed in $1 \%$ osmium tetroxide in $0.1 \mathrm{M}$ phosphate buffer $\mathrm{pH} 7.3$ at $4 \mathrm{oC}$, dehydrated using a graded acetone series and embedded in Araldite 6005. Semi-thin sections were stained with toluidine blue and examined under light microscope. Ultra-thin sections(60-90nm) were stained with uranyl acetate and lead citrate and examined with JEOL transmission electron microscope at 60 or $80 \mathrm{kV}$, after which the electron micrographs were taken, developed and printed for investigation . The current ultrastructure work was achieved in the electron microscope unit of Faculty of Science, University of Ain Shams, Cairo.

\section{III- Statistical Analysis}

Statistical analysis was achieved using the computerbased statistics program SPSS. The current parameters were analyzed by a one-way ANOVA test (Lindman, 1974), whereas the level of significance was estimated taking the probability $(\mathrm{p}<0.05)$ as a minimal requirement for significance. All the present data were presented as means \pm standard error.

\section{Results}

\section{I- Renal Gross Anatomical results}

The kidneys of all the studied fish species were paired retroperitoneal organs. They situated within the abdominal cavity just ventral to the vertebral column. For both Tilapia zilli and Scomber japonicus, the kidneys were slender, elongated organs, occupying a significant portion of the trunk. They were mostly fused along their entire length forming a continuous mass. While the kidneys of Bagrus bayad were relatively short broad organs. Each kidney composed of two main portions, the head and the trunk kidneys, whereas they were not grossly distinguishable. However, in the present investigation the considered kidney was the trunk kidney. It represented the proper excretory organ.

\section{II- Renal Morphometric results}

The recorded data concerning with the number, size of the glomeruli as well as the glomerular filtration surface area of the kidney of the various selected fish species were tabulated in table (1). The number of glomeruli were distinctly varied, with Bagrus bayad having the greatest number ( $7360 \pm 784.8$ and $11.16 \pm 1.19)$ followed by Tilapia zilli $(4174 \pm 444.6$ and $6.33 \pm 0.84)$ then Scomber japonicus $(2967 \pm 316$ and $4.50 \pm 1.70)$ which exhibited the fewest number either per gram renal tissue or per each microscopic field respectively. The differences in the number of glomeruli were significant $(\mathrm{P}<0.01$ and $\mathrm{P}<0.001$ ) when compared the number of glomeruli of Bagrus baydd with either'reparpation $i l l i$ or Scomber japonicas, respectively.

\section{III- Histological observations}

The trunk kidneys were comprised of well differentiated nephrons along with variable quantities of hemopoietic and lymphoid tissues in the interstitium. Although all the examined kidneys exhibited approximately similar basic histological renal organization, many considerable differences were detected. The glomeruli of both Bagrus bayad and Tilapia zilli were distributed within the renal tissue as clusters in which there were 4-6 glomeruli for Bagrus bayad and 3-5 glomeruli in each cluster for Tilapia zilli repectively. In contrast, the glomeruli of Scomber japonicus were distinctly few and obviously small which dispersed within the renal interstitium see figure (1).

Each nephron was consisted of a renal corpuscle and renal tubules. The renal corpuscle was roughly spherical shaped structure consisting of a Bowman's capsule, which formed of a cup-shaped double layered structure that enclosing the glomerulus. The glomerulus was a globular network of densely packed anastomosing capillaries which invaginated Bowman's capsule as shown in figure (2).

The proximal convoluted tubule was composed of two segments, the first and second proximal segments which were varied in the heights of their epithelial lining and density of brush border. The lumen of both segments contain amorphous material. While the distal tubules were narrow in diameter and not as frequently in sections as proximal tubules. Their epithelial lining were large cubical epithelia and their lumens were relatively enlarged comparing to those of proximal tubules (fig. 3).

The collecting tubules were quite large, their lining were simple high cubical epithelium with centrally located spherical shaped nucleus. Generally, the distal and collecting tubules had much wider lumens than the proximal tubules. In addition, the cross sections of the collecting tubules were larger than those of the proximal and distal tubules. Moreover, the diameters of the cross sections of the different segments of the renal tubules of Bagrus bayad were markedly larger with wider lumens comparing to either Tilapia zilli or Scomber japonicus. The later species exhibited the smallest diameters and narrowest 
lumens of the various segments of the renal tubules among the selected fish species see figure (3).

\section{IV- Ultrastructure observations of the Kidney}

The ultrastructural investigation of the renal corpuscles showed that the capillary loops of the glomeruli of the various studied fish species were lined with attenuated and fenestrated endothelial cells. The mesangial cells were situated peripherally and among the walls of the capillary loops. Scomber japonicus showed abundance of mesangial cells in comparison with either Bagrus bayad or Tilapia zilli (fig. 4).

The processes of the podocyte of freshwater fish species, Bagrus bayad gave rise to pedicels that enclose certainly wide filtration slits. In contrast, the podocyte surface of the seawater fish species, Scomber japonicus, lied flat on the glomerular basement membrane and the foot processes were hardly seen. The filtration slits of the Scomber japonicus were extremely narrow, while those of Tilapia zilli were moderate in size.

The filtration barrier of the freshwater fish species was relatively thin comparing to those of brackish water and seawater fish species see figure (5).

The podocytes of the visceral epithelial layer were irregular in shape and contained distinctly large nucleus. Its size and composition were markedly varied among different studied fish species, with freshwater fish species having the largest nucleus, numerous mitochondria and endoplasmic reticulum comparing to the other species see figure (6).

The epithelial lining of the first proximal segment were tall columnar epithelium with large oval basally located nucleus and high density of relatively long apical microvilli. Bagrus bayad showed huge number of relatively small mitochondria followed by Tilapia zilli then Scomber japonicus which exhibit the fewest number and the largest mitochondria. Microvilli of Tilapia zilli were relatively shorter and closely packed comparing to both Bagrus bayad and Scomber japonicus. In addition, the epithelial lining of the first proximal segment displayed very shallow basal infoldings associated with numerous mitochondria scattered all over the cytoplasm as shown in figure (7).

In contrast, the lining epithelium of the second proximal segment was higher columnar epithelium with centrally located nucleus. They showed relatively short less densely packed apical microvilli and especially prominent deep basal infoldings. It was distinguished by the abundance of mitochondria distributed throughout the cytoplasm. However, the relative extent of the infoldings of the basal cell membranes as well as the number and size of mitochondria were markedly varied with seawater fish species, Scomber japonicus had the most complicated basal infoldings associated with unique giant mitochondria surrounded by lamellar structures. While Telapia zilli showed the greatest number of mitochondria and Bagrus bayad exhibited the simplest basal infolding and the longest apical microvilli (fig. 8).

The distal tubules of all the examined fish species were lined with cubical epithelium with large oval shaped centrally located nuclei. They were devoid of microvilli . The distal tubule of the freshwater Bagrus bayad, displayed numerous round moderate sized mitochondria scattered throughout the cytoplasm and extremely shallow basal infolding. On the other hand, the distal tubule of the brackish water fish species, Tilapia zilli showed huge number of relatively small round and elongate mitochondria associated with a well developed tubular system. While the distal tubule of the seawater fish species, Scomber japonicus exhibited moderately developed basal infolding and many giant size rounded and rod-like shaped mitochondria with closely packed cisternae which located mainly around the nucleus. However, the mitochondria of seawater fish were not as abundant as in either freshwater or brackish water fish species see figure (9).

\section{Discussion}

In the present investigation, the trunk kidney of the different examined fish species was composed of nephrons along with hematopoietic tissue dispersed throughout the organ. Such observation is in a good agreement with the findings of Ojeda et al. (2003).

In the current work, the distribution of the glomeruli within the renal tissues of the different investigated species was certainly varied, with the glomeruli of Bagrus bayad and Tilapia zilli were grouped as clusters, each of which contained 4-6 glomeruli for Bagrus bayad and 3-5 glomeruli for Tilapia zilli respectively. Such findings go parallel with the results of Morovvati et al.( 2011) on $C$. idella. They reported that the glomeruli of the different fish species were grouped in small clusters.

On contrast, the glomeruli of Scomber japonicus were scattered throughout the renal tissue which appeared as small oval or spherical shaped structures. The present observations are in agreement with those of Anderson \& Lowen (1975) who mentioned that many teleostean kidneys consist of dispersed glomeruli .

In the present work, Bugrus bayad showed relatively numerous, well-vascularized large glomeruli. While Tilapia zilli showed moderate number and size of glomeruli comparing to both freshwater and seawater species, Scomber japonicus. The latter displayed the fewest number and the smallest size of glomeruli. Such findings are confirmed through the observations of Ford (1958) who reported that pink salmon fry reared in fresh water had more glomeruli than those reared in salt water. Further support of such results comes from the study of García et al. (2013) who mentioned that kidneys of freshwater teleost 

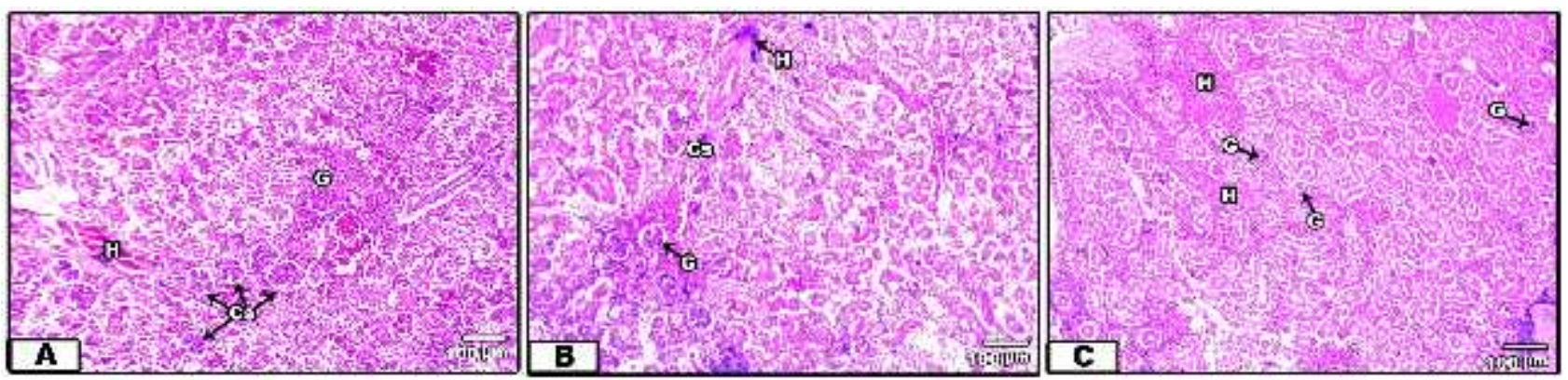

Fig.1 : Photomicrograph of transverse paraffin sections of the trunk kidney of the freshwater fish species, Bagrus bayad (A), the brackish water fish species, Tilapia zilli (B) and the seawater fish species, Scomber japonicus (C) showing nephrons along with haemopiotic tissue $(\mathrm{H})$. Note the distribution of the nephrons as clusters in both Bagrus bayad and Tilapia zilli (CS) or scattered

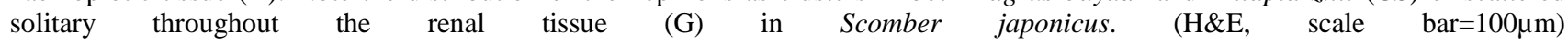
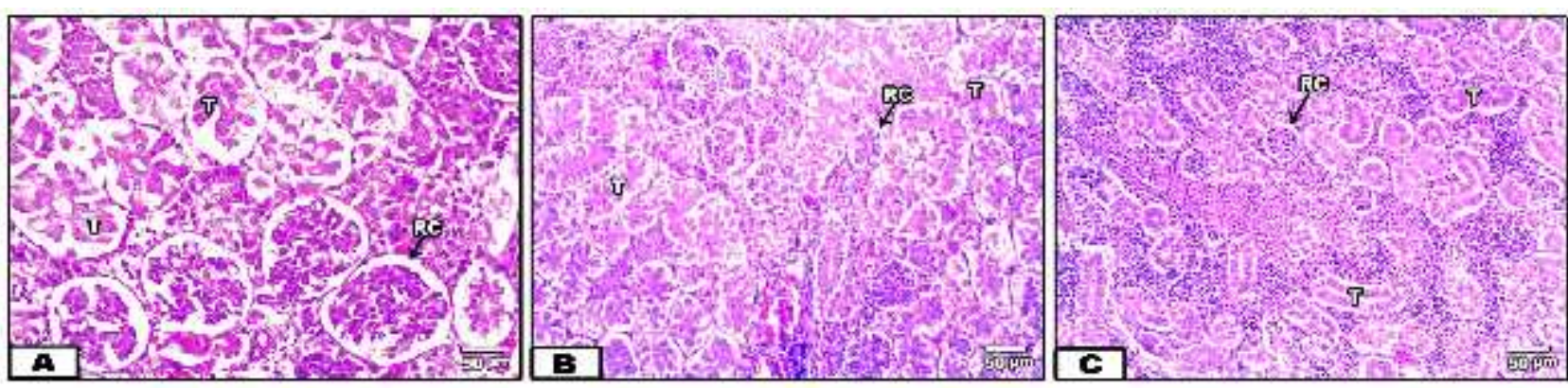

Fig.2: Photomicrograph of transverse paraffin sections of the trunk kidney of the freshwater fish species, Bagrus bayad (A), the brackish water fish species, Tilapia zilli (B) and the seawater fish species, Scomber japonicus (C) showing the relatively large size of the renal corpuscles (RC) of Bagrus bayad and the small size of (RC) of Scomber japonicus as well as cross sections of different renal tubule segments $(\mathrm{T})$. (H\&E, scale bar $=50 \mu \mathrm{m})$.
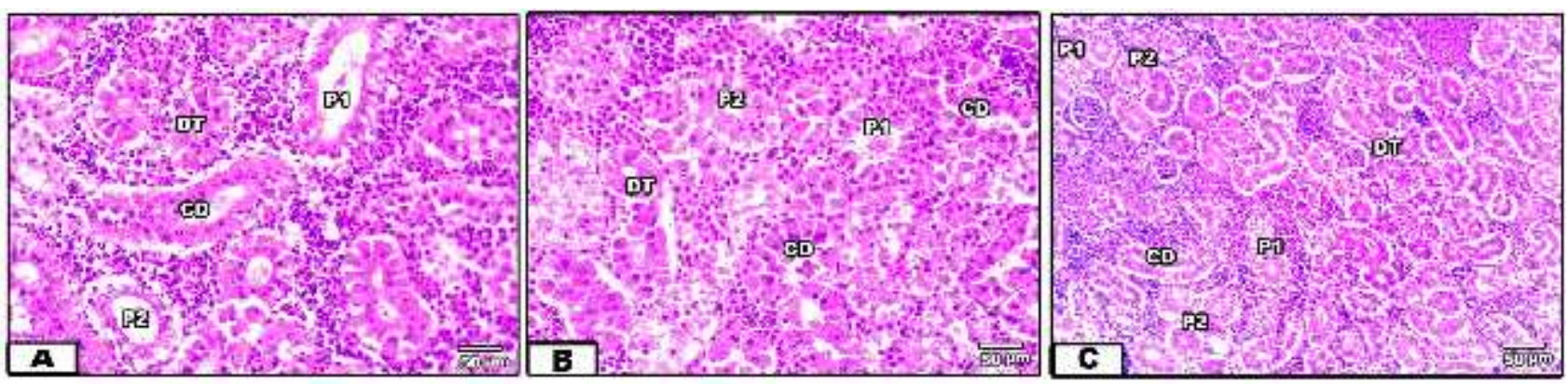

Fig.3: Photomicrograph of transverse paraffin sections of the trunk kidney of the freshwater fish species, Bagrus bayad (A), the brackish water fish species, Tilapia zilli (B) and the seawater fish species, Scomber japonicus (C) showing the variable size and thickness of the cross sections of the first proximal (P1), second proximal (P2), distal tubule (DT) and collecting duct (CD). (H\&E, scale bar $=50 \mu \mathrm{m})$.

Table(1) : Number of glomeruli per gram renal tissue, per each microscopic field, size of glomeruli and glomerular filtration surface area of freshwater fish species (Bagrus bayad), brackish water fish species (Tilabia zilli) and seawater fish species (Scomber japonicus).All the data are represented as means \pm standard errors. Number in parentheses are the number of the selected fishes.

\begin{tabular}{|c|c|c|c|c|}
\hline Selected fishes & $\begin{array}{c}\text { No. of glomeruli } \\
\text { (Per g renal tissue) }\end{array}$ & No. of glomeruli. & $\begin{array}{c}\text { Size of glomeruli. } \\
\left(\mathrm{mm}^{3}\right)\end{array}$ & $\begin{array}{c}\begin{array}{c}\text { Filteration surface area. } \\
\left(\mathbf{m m}^{2}\right)\end{array} \\
\end{array}$ \\
\hline 1-Byad (Bagrus bayad) (15) & $7360 \pm 784$ & $11.16 \pm 1.1$ & $\overline{186.36} \pm 18.55$ & $22034 . .50 \pm 201.88$ \\
\hline 2-Green tilabia Tilabia zilli)(15) & $4147 \pm 444.6$ & $6.33 \pm 0.84$ & $40.34 \pm 7.5$ & $265 \pm 24.4$ \\
\hline $\begin{array}{l}\text { 3-Chub mackerel } \\
\text { japonicus) (15) }\end{array}$ & $2967 \pm 316$ & $4.50 \pm 1.7$ & $3.2 \pm 0.39$ & $14.42 \pm 2.8$ \\
\hline $\begin{array}{l}\text { Probability } \\
\text { (1)vs(2) }\end{array}$ & $\begin{array}{l}\text { P } \\
\text { O.01 }\end{array}$ & $\begin{array}{l}\text { P } 0.01 \\
\text { S }\end{array}$ & $\begin{array}{l}\text { P } 0.001 \\
\text { S }\end{array}$ & 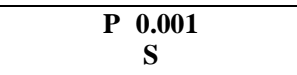 \\
\hline (1)vs(3) & $\begin{array}{l}\text { P } 0.001 \\
\text { S }\end{array}$ & $\begin{array}{l}\text { P } 0.001 \\
\text { S }\end{array}$ & $\begin{array}{l}\text { P } 0.001 \\
\text { S }\end{array}$ & $\begin{array}{l}\text { P } 0.001 \\
\text { S }\end{array}$ \\
\hline (2)vs(3) & $\begin{array}{l}\text { P 0.05 } \\
\text { NS }\end{array}$ & $\begin{array}{l}\text { P } 0.05 \\
\text { NS }\end{array}$ & $\begin{array}{l}\text { P } 0.01 \\
\text { S }\end{array}$ & $\begin{array}{l}\text { P } 0.05 \\
\text { NS }\end{array}$ \\
\hline
\end{tabular}



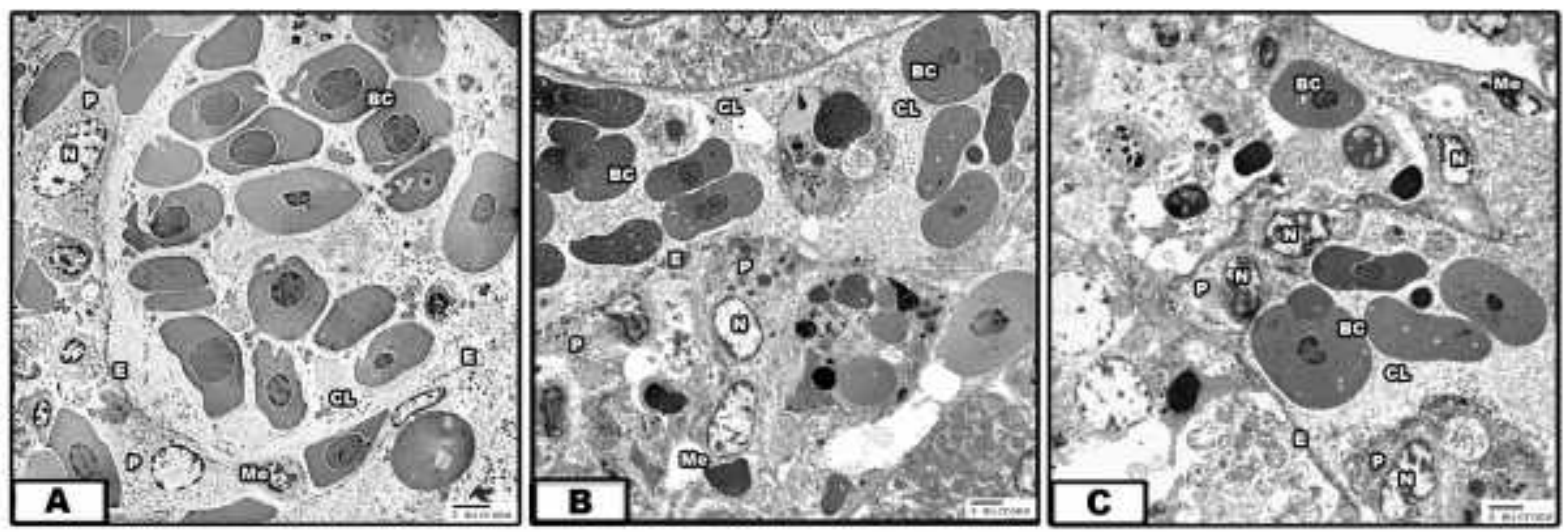

Fig.4 - Transmission electron micrograph of the renal corpuscles of the freshwater fish species, Bagrus bayad (A), the brackish water fish species, Tilapia zilli (B) and the seawater fish species, Scomber japonicus (C) showing the capillary loops (CL) containing blood corpuscles $(\mathrm{Bc})$ and lining with fenestrated endothelium $(\mathrm{E})$, mesengial cells $(\mathrm{Me})$ and podocytes $(\mathrm{P})$ with large nuclus $(\mathrm{N})$. Note the differences in the size of capillary loops and the podocytes. ( scale bar=2microns) .
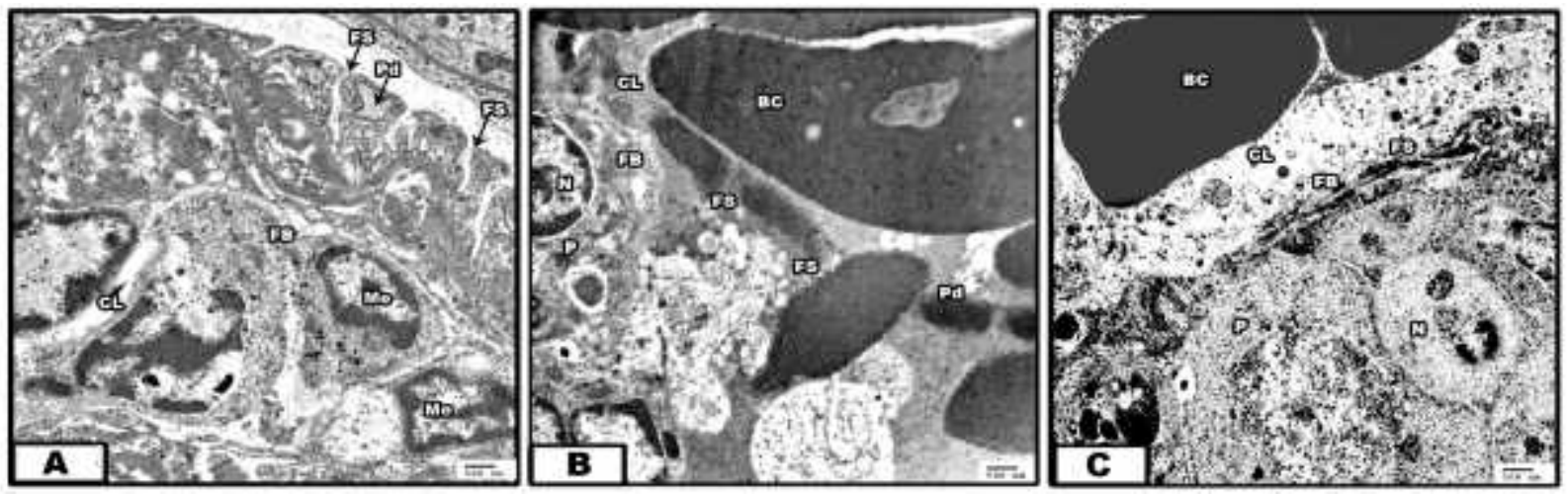

Fig.5 - Transmission electron micrograph of a magnified renal corpuscle of the freshwater fish species, Bagrus bayad (A), the brackish water fish species, Tilapia zilli (B) and the seawater fish species, Scomber japonicus (C) showing pedicles (pd), filtration barrier (FB) with filtration slits (FS). Note the variations in the thickness of (FB) and width of (FS).
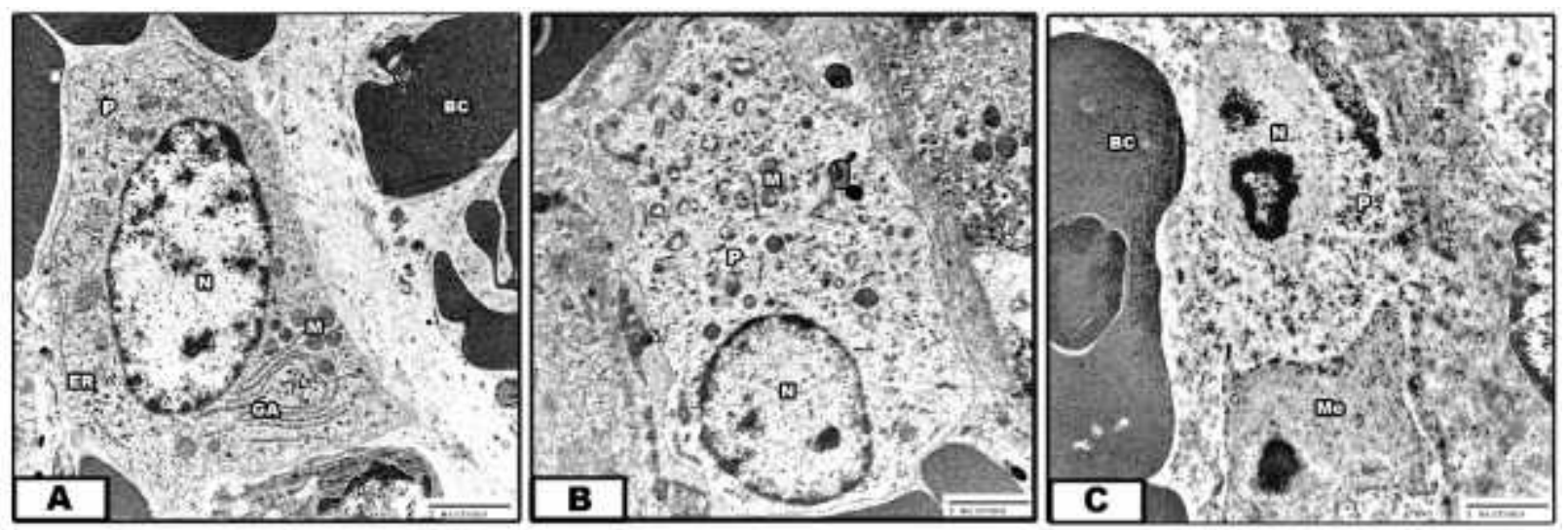

Fig.6 - Transmission electron micrograph of a high magnified renal corpuscle of the freshwater fish species, Bagrus bayad (A), the brackish water fish species, Tilapia zilli (B) and the seawater fish species, Scomber japonicus (C) showing the podocytes with large nucleus (N), mitochondria (M), Golgi apparatus (GA) and endoplasmic reticulum (ER). Note the cell organelles are well developed in Bagrus bayad and hardly seen in Scomber japonicus. 

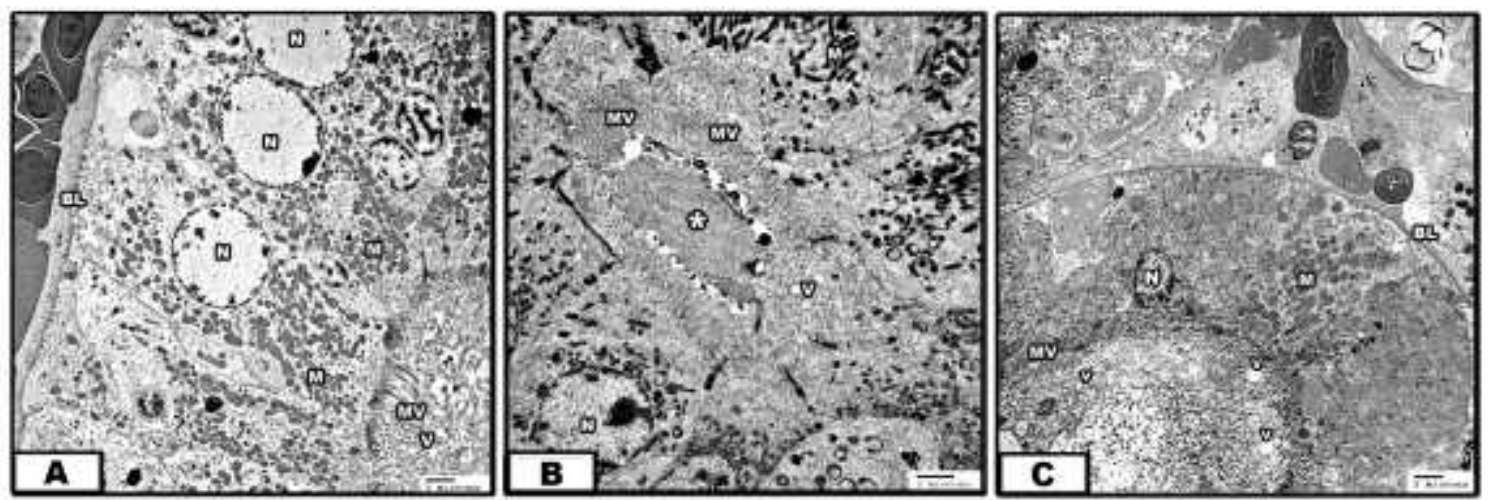

Fig.7 - Transmission electron micrograph of the epithelial lining of the first proximal tubule segment of the freshwater fish species, Bagrus bayad (A), the brackish water fish species, Tilapia zilli (B) and the seawater fish species, Scomber japonicus (C) showing apical closely packed microvilli (Mv), numerous mitochondria (M), spherical shaped nucleus (N), basal lamina (BL) and vacuoles (v).
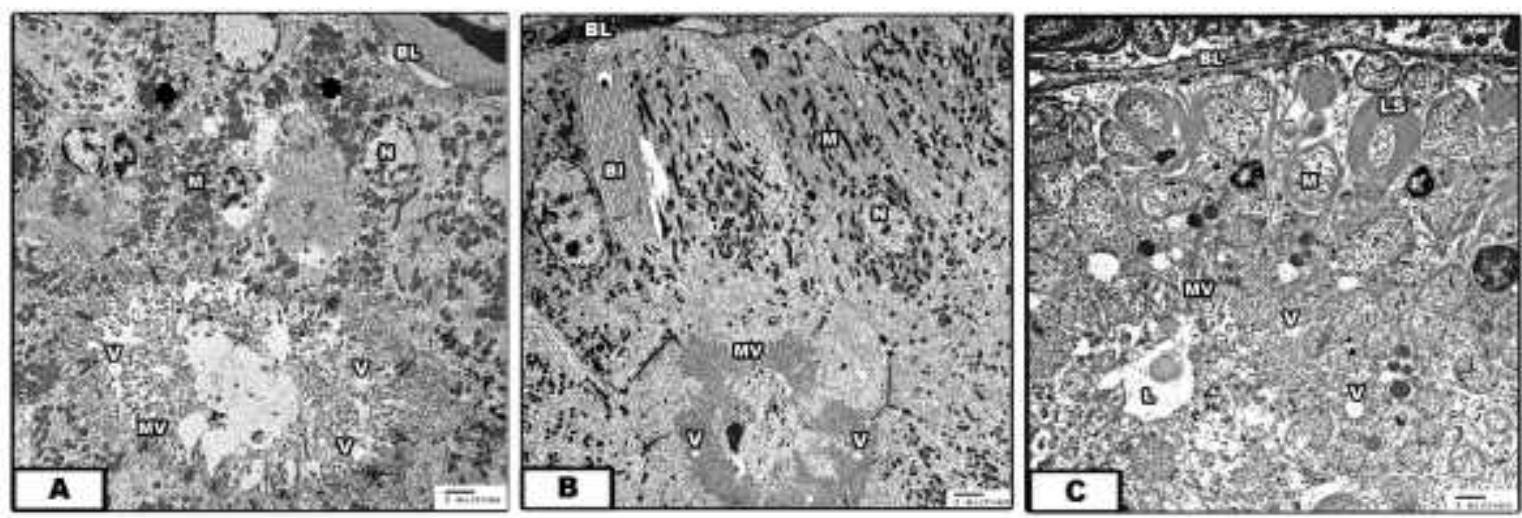

Fig.8 - Transmission electron micrograph of the epithelial lining of the second proximal tubule segment of the freshwater fish species, Bagrus bayad (A), the brackish water fish species, Tilapia zilli (B) and the seawater fish species, Scomber japonicus (C) showing the relatively less densely packed microvilli $(\mathrm{Mv})$, numerous mitochondria $(\mathrm{M})$, nucleus (N),basal lamina (BL) and vacuoles (v). Note the well developed basal infolding (BI) in both Tilapia zilli and Scomber japonicas which formed lamellar structures (LS) enclosing the mitochondria in Scomber japonicus.
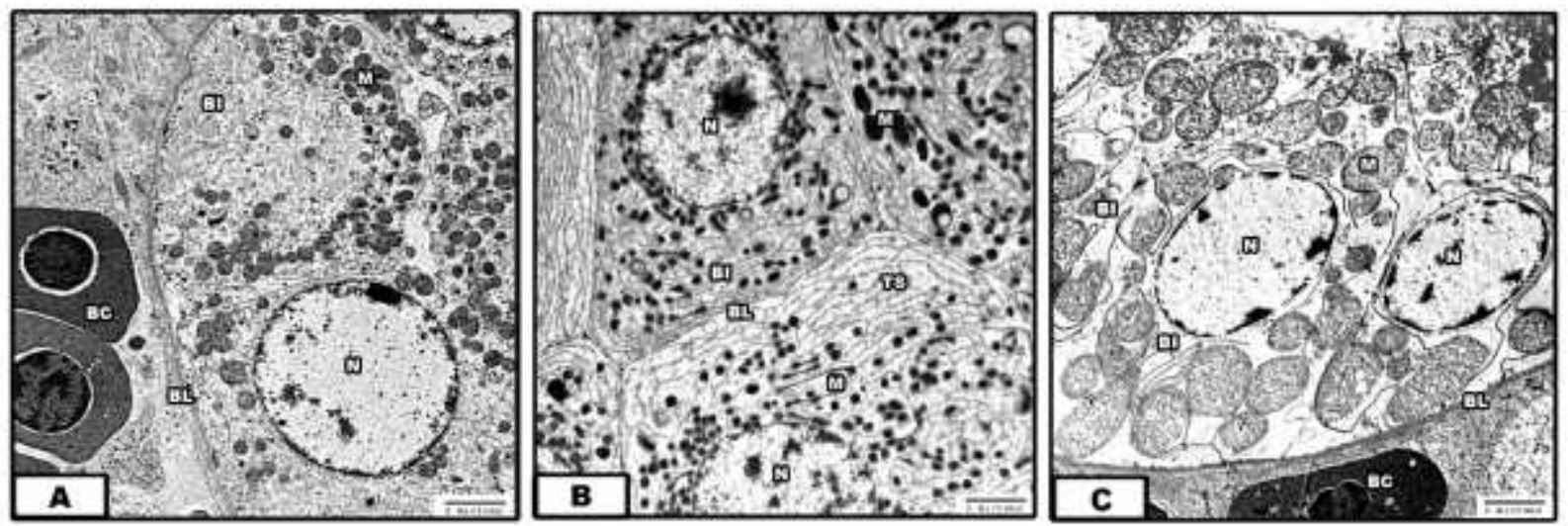

Fig.9 - Transmission electron micrograph of the epithelial lining of the distal tubule segment of the freshwater fish species, Bagrus bayad (A), the brackish water fish species, Tilapia zilli (B) and the seawater fish species, Scomber japonicus (C) showing the relatively large oval nucleus $(\mathrm{N})$, numerous mitochondria $(\mathrm{M})$, various thickness of basal lamina (BL) and basal infoldings (BI). Note well developed tubular system (TS) in Tilapia zilli and giant size mitochondria in Scomber japonicus . 
had numerous nephrons to elaborate large volume of highly diluted urine and retain electrolytes.

In addition, the numerous large size glomeruli characteristic to Bagrus bayad are consistent with the study of Wong\&Woo (2006) who referred that sea bream fish exhibited significant increase in glomerular number and size when exposed to hypo-osmotic media which could facilitate water excretion. Further confirmation of the present recorded data comes from the results of Evans \& Claiborne (2009) who reported that the kidneys of the freshwater acclimated Juvenile goliath grouper had numerous nephrons with well-organized renal corpuscles.

In the current investigation, the organization of the renal tubules of both freshwater fish and brackish water fish species are in agreement with the results of Sakai (1985) on a freshwater teleost, crucian carp, Carassius auratus, Evans \& Claiborne (2009) on Juvenile goliath grouper who found that the structure of the kidney of aforementioned studied species showed well organized renal tubules.

Numerous studies have been designed to correlate the renal morphological pattern with its performed function. In marine bony fishes, there is no reason to pump out large amounts of nephric filtrate at the glomerulus since they exposing to constant danger of dehydration by the hypertonic seawater media. Therefore, it is not surprising that many bony fishes have few number and small size of glomeruli and even some have no glomeruli at all ( Ozaka et al., 2009). By contrast to marine fish species, there are numerous well vascularized glomeruli with high glomerular filtration rate in freshwater fish species (Holmes \& Mcbean, 1963).

The measurements of glomerular size and glomerular filtration surface area (Charmi et al., 2009) strongly indicated that the filtration surface area expressed per square micro meter of body surface is significantly greater in freshwater forms comparing to those of seawater forms.

In the present investigation, the higher recorded values of the glomerular size and glomerular filtration surface area of the freshwater fish species may strongly reflected high glomerular filtration rate characteristic to freshwater fishes, Bagrus bayad comparing to Tilapia zilli and Scomber japonicus.

The fine structure of the renal corpuscle of the studied fish species showed that the capillary loops of the glomeruli were lined with attenuated fenestrated endothelial cells. Since the mesengial cells have vasoconstrictor role on Mugil cephalus and Liza saliens (Morales et al., 1990). Thereby, the greater number of mesengial cells characteristic to seawater fish species may constricted the glomerular arterioles to some extent which affects the filtration rate and thus protects against loss of water.
The podocytes displayed irregular shape with distinctly large nucleus. Its size and composition were markedly varied among different studied fish species, with freshwater fish species having the largest nucleus, numerous mitochondria and endoplasmic reticulum comparing to the other species. The processes of the podocyte of freshwater fish species, Bagrus bayad gave rise to pedicels that enclose certainly wide filtration slits.

In contrast, the podocyte surface of Scomber japonicus lied flat on the glomerular basement membrane, a situation which may be reflected a lower glomerular filtration rate. The filtration slits of the Scomber japonicus were extremely narrow, while those of Tilapia zilli were moderate in size. The filtration barrier of the freshwater fish species was relatively thin comparing to those of brackish water and seawater fish species.

The first proximal segment of all examined species exhibited high density of relatively long apical microvilli along with large light vacuoles and many lysosomes and a shallow basal infoldings with numerous number of mitochondria. While the second proximal segment showed relatively short less dense apical brush border of microvilli and well developed deep basal infoldings.

The density of microvilli as well as the number and size of mitochondria are markedly varied among the examined fish species, with brackish water fish species exhibited the greatest density of microvilli while the seawater fish species displayed the largest size of mitochondria. In addition, their basal infoldings were extended deeply within the cytoplasm which formed lamellar structures enclosing the mitochondria. Such characteristic features may enable the studied fish species to maintain water/electrolyte balance of their body fluids regardless to the nature of their habitat.

In the current investigation, the distal tubules of the examined fish species were devoid of microvilli and characterized by numerous elongated and rounded large mitochondria. The size and the abundance of the mitochondria and the degree of the complexity of the basal infoldings as well as the thickness of the basal lamina of the distal tubule were certainly varied, with the seawater fish species, Scomber japonicus having the largest size of mitochondria and the thickest basal lamina in comparison to the other two fish species.

The present findings concerning the ultrastrucural aspects of the nephron of the different selected fish species go parallel with the results of Anderson \& Loewen (1975) on freshwater trout, Zuasti et al. (1983) on Sparus auratus, Morales et al.(1990) on Mugil cephalus and Liza saliens, Mohinder et al. (2014) on Latimeria chalumnae. 
In conclusion, the results of the current study showed that the examined fish species exhibited specific adaptive renal structural features to fulfill their osmoregulatory demands in their various habitats.

\section{References}

Abdullahi, S. A. and Abolude, D. S. (2001). Some stu on the biology of Bagrus bayad (Daget) in Tiga Dam, Kano state Nigeria. J. Arid- zone fisheries, 1: 1-11.

Akhundov, M. M. and Fedorov, K.E. ( 1995). Effects of exogenous estradiol on the formation of ovaries in juvenile sterlet Acipenser ruthenus. J. Ichthyology, 35: 109-120.

Altschuler, E. M. ; Nagle, R. B.; Braun, E. J.; Lindstedt, S. L. and Krutzsch, P. H. (1979). Morphological study of the desert heteromyid kidney with emphasis on the genus perognathus. Anat. Rec., 194 : 461-468.

Anderson, B.G. and Lowen, R.D. (1975). Renal morphology of freshwater trout. Am. J. Anat .,143: 93-114.

Bancroft, J. D. and Gamble, B. (2002). Theory and practice of histological techniques. Philadelphia (PA): Churchill Livingstone.

Bonga, S. E. (1973). Morphometrical analysis with the light and electron microscope of the kidney of the anadromous three-spined stickleback Gasterosteus aculeatus, form trachurus, from fresh water and from sea water. Z. Zellforsch. Mikrosk. Anat., 137:563-588.

Cataldi, E.; Ciccotti, E. ; Dimarco, P. ; Disantano, O. ; Bronzi, P. and Cataudella, S. (1995). Acclimation trials of juvenile Italian Sturgeon to different salinities : morphophysiological descriptors. J. Fish Biol., 47: 609-618.

Charmi, A.; Bahmani, M.; Sajjadi, M. M. and Kazemi, R. (2009). Morpho-histological study of kidney in farmed juvenile beluga, Huso huso (Linnaeus, 1758). Pakistan J. Biol. Sci., 12: 11-18.

Charmi , A.; Parto , P.; Bahmani , M. and Kazemi , R. (2010). Morphological and histological study of kidney in juvenile great sturgeon. (Huso huso) and persian sturgeon (Acipenser persicus). American-Eurosian J. Agric. Environ. Sci., 7:505-511.

Crutchfield, J.U.; Schiller, D.H.; Herlong,D.D and Mallin, M.A. (1992) . Establishment and impact of redbelly tilapia in a vegetated cooling reservoir. J. Aquatic Plant Manag.,30:28-35.

Dantzler,W. H.(2003). Regulation of renal proximal and distal tubule transport: sodium, chloride and organic anions. Comp.Biochem.Physiol., 136:453-478.

Das, S. and Srivastava, G.J. (1980). Structural changes in the kidney of freshwater mud eel Amphipnous cuchia (Ham.) subjected to different osmotic conditions. Arch. Anat. Microsc. Morphol. Exp., 69:109-121.

Drummond, I.A. (2000). The zebrafish pronephros: A genetic system for kidney development. Pediatr. Nephrol., 14:428-435.

Engelund, M.B. and Madsen, S.S.(2011). The role of aquaporins in the kidney of euryhaline teleosts. Front Physiol., 23:2-51.
Evans, D.H. and Claiborne, J.B. (2009). Osmotic and ionic regulation in fishes. In: Evans DH, editor. Osmotic and ionic regulation: cells and animals. Boca Raton: CRC Press.pp.295-366.

Evans, D.H.; Piermarini , P.M. and Choe, K.P. (2005). The multifunctional fish gill: Dominant site of gas exchange, osmoregulation, acid-base regulation, and (Hizeretion of nitrogenous waste. Physiol. Rev. J., 85:97177.

Ford, P. and Newstead, J.D. (1958). Studies on the development of the kidney of the Pacific pink salmon, (Oncorhynchus gorbuscha (Walbaum): I. The development of the pronephros. Can. J. Zool., 36: 15-21.

García , L.N.; Sierra ,C.L.; Perez, J.; Esquivel, F.and Chapman , F.A.(2013). Osmoregulation of juvenile marine goliath grouper (Epinephelus itajara) in lowsalinity water. Rev.Colomb. Cienc. Pecu ., 26:127-135.

Hawkins, G. S.; Galvez, F. and Goss, G. (2004). Seawater acclimation causes independent alterations in $\mathrm{Na}+\mathrm{K}+-$ and $\mathrm{H}+-$ ATPase activity in isolated mitochondriarich cell subtypes of the rainbow trout gill. J. Exp. Biol., 207: 905-912.

Hentschel , H. and Elger, M. (1988). The distal nephron in the kidney of fishes, Advances in Anat.Embryo. Cell Biol., 108:1-151.

Hwang, P. P. and Lee, T. H. (2007). New insights into fish ion regulation and mitochondrion-rich cells. Comp. Biochem. Physiol., 148:479 -497.

Jarial , m.s. And wilkins, j.h. (2010). Structure of the kidney in the coelacanth latimeria chalumnae with reference to osmoregulation. J. Fish. Biol., 76:655-668.

Jensen , M. K.; Madsen, S. S. and Kristiansen, K. (1998). Osmoregulation and salinity effects on the expression and activity of $\mathrm{Na}+\mathrm{K}+-$ ATPase in the gills of European sea bass Dicentrarchus labrax. J. Exp. Zool., 282 : 290 - 300.

Koc , N.D. ( 2006). The comparative research of kidneys of Rainbow Trout (Oncorhynchus mykiss Walbaum, 1792) and Rat (Ratlus norvegicus Berkenhout, 1769) in Morphometric and Histologic Manner. Pakistan J. Biol. Sci., 9: 445-447.

Kunkel, P.A. (1930). The number and size of glomeruli in the kidney of several mammals. Bull. Johns. Hosp., 47: 285.

Lindman,H. R. (1974). Analysis of variance in complex experimental designs. San Francisco: W. H. Freeman \& co.Hillsdale,NJ USA:Erlbaum.

Malami, G.Z. and Magawata, I. (2010). Analysis of food and feeding habits of catfish (Bagrus bayad, Macropterus (Daget) in River Rima and Goronyo Dam, Sokoto State, Nigeria. Nigerian J. of Basic Appl. Sci., 18: 277-284.

Maluf, N. S. R. (1991). The kidney of Tapirs: A macroscopical study. Anat. Rec., 231: 48-62.

Mohinder, S. J.;Vincent H. G. and John H. W.(2014). Ultrastructural Study of the Kidney in the Coelacanth Latimeria chalumnae (Rhipidistia: Coelacanthini). Zool. Sci., 31:283-291. 
Morales, E.L.; Meseguer,

J.; Lozano,

Sakai ,T. (1985). The structure of the kidney from M.T.and Agulleiro, B.(1990). Ultrastructure of the nephron of grey mullets (Mugil cephalus L. and Liza saliens Risso 1810). Anat. Anz., 170 :49-61.

Morovvati , H . ; Erfani majd, N . ; Peyghan , R . and Mobaraki , G.H. (2011). Histological study of excretory portion of kidney in Grass carp (Ctenopharygodon idella) Iranian J. Vet. Med., 6 :69-75.

Ogawa , M. (1962) . Comparative study on the internal structure of the teleostean kidney. Science Reports of the Saitama University, $4: 107-129$.

Ojeda, J.L.; Icardo, J.M. and Domezain, A. (2003). Renal corpuscle of the sturgeon kidney: an ultrastructural, chemical dissection and lectin-binding study. Anat. Rec., 272: 563-573.

Ojeda, J. L.; Icardo, J.M.; Wong, W. P. and Yuen, K. (2006). Microanatomy and ultrastructure of the kidney of the African lungfish Protopterus dolloi. Anat. Rec., 288: 609-625.

Ozaka,C.; Yamamoto,N. and Somiya ,H.(2009). The a glomerular kidney of the deep-sea fish, Ateleopus japonicus (Ateleopodiformes: Ateleopodidae): Evidence of wider occurrence of the a glomerular condition in teleostei, 3:609-617.

Prashanth, M. S. (2011). Histopathological changes observed in the kidney of freshwater fish, cirrhinus mrigala (hamilton) exposed to cypermethrin. Recent Res. Sci. Technol., 3: 59-65.

Reimschuessel, R.( 2001), A fish model of renal regeneration and development. ILAR J., 42:285-291.

Rizkalla,S. I. and Faltas, S.N. (1997). Feeding habits of Chub Mackerel (Scomber japonicus) in the Egyptian Mediterranean waters. J.K.A.U. Mar. Sci., 8: 127-136. 
